\title{
Women, Engagement, Stress, and Worry: Do they have to go hand in hand?
}

\section{Dr. Denise Wilson, University of Washington}

Denise Wilson is a professor of electrical and computer engineering at the University of Washington, Seattle. Her research interests in engineering education focus on the role of self-efficacy, belonging, and other non-cognitive aspects of the student experience on engagement, success, and persistence and on effective methods for teaching global issues such as those pertaining to sustainability. 


\title{
Women, Engagement, Stress, and Worry: Do they have to go hand in hand?
}

\begin{abstract}
Much of the engagement research in higher education focuses on positive measures of student engagement in terms of how students spend their time and the level to which they are exposed to effective teaching practices. In contrast, few studies have focused on the affective or emotional components of engagement. This study complements existing studies by looking at demographic differences in both positive and negative measures of emotional engagement across gender, race/ethnicity, international student status, and family education. Positive emotional engagement captures how much students enjoy learning and how interested they are in their coursework, and negative emotional engagement captures feeling worried, anxious, or discouraged.

Demographics and emotional engagement items were self-reported by students via a survey distributed within seven large sophomore-level engineering courses at a large public institution $(N=781)$. Hierarchical linear regression models demonstrated that none of the demographic categories predicted positive emotional engagement. In contrast, being female or being a nonWhite or non-Asian under-represented minority (URM) predicted negative emotional engagement. However, for those female and URM students who interacted frequently with faculty or teaching assistants (TAs), the gap in negative emotional engagement between them and their majority (male or White) peers disappeared. This has strong implications for both faculty and TA professional development. It also strengthens support for further research that emphasizes both how students feel through emotional engagement as well as what they do through more traditional measures of engagement.
\end{abstract}

\section{Introduction}

This study investigates the role of gender, race/ethnicity, first-generation status, and international student status in engagement in engineering classrooms. We also consider the effect of instructional support and interactions in the relationships between demographic groups and multiple forms of emotional engagement that students report in the engineering classroom. Demographic categories of interest were chosen based on how the existing literature has identified student groups in engineering who are likely to struggle more or be disadvantaged compared to majority White male students.

Gender: Women make up 58.2\% [1] of the population in the United States yet earn only 19.8\% of all bachelor's degrees in engineering and 24.2\% of masters degrees [2] [3]. In the workforce, they represent only $14.5 \%$ of engineers [4]. Despite extensive efforts to reach gender parity in engineering [5], engineering remains stubbornly resistant to providing a compelling and welcoming environment for women while other fields like biology and math have advanced to much greater gender balance at $60 \%$ and $42 \%$ of bachelor's degrees granted to women respectively [6]. Women bring diversity of thought to engineering and their continuing underrepresentation in these disciplines introduces a cost - "... in products not built, in designs not considered, in constraints not understood, in processes not invented." [7]. 
Race/Ethnicity: Racial and ethnic minorities also struggle to gain a foothold in engineering. Black and Hispanic individuals of both genders are under-represented in the STEM workforce compared to their representation in the overall workforce. Limited access to a high quality education, discrimination, and lack of encouragement continue to hamper efforts to recruit and retain more of these minorities in engineering jobs [8].

First-Generation Status: Those students who are the first in their family to attend college also join the under-represented ranks in engineering. While $56 \%$ of undergraduates were firstgeneration college students in 2015-2016, students who are not first-generation can outnumber first-generation students in engineering by $2: 1$ [9]. The identities, interests, performance, family support, and self-efficacy of these students are often different than students who come from families with college experience, thus altering the internal landscape and comfort levels of these students in engineering classrooms [10].

International Status: While women, racial/ethnic minorities, and first-generation college students have been studied extensively in the higher education literature, studies of international students are lacking in some part due to the presumption that these students do not face the biases and barriers that domestic URM students face. Yet, despite over one million international students attending college in the U.S. that make up 5.5\% of the U.S. higher education population [11], international students from a wide range of countries and cultures face barriers ranging from cultural intolerance to inhospitality and unfairness. And, contrary to popular belief, these barriers are not just a matter of taking time to adjust to American culture [12].

Overcoming these barriers and increasing the representation of under-represented groups while also stabilizing and supporting those who enter our educational system from other cultures is critical to maintaining a healthy and diverse engineering workforce. Engaging these students in their education and courses is a critical first step in welcoming and maintaining them in our degree programs, and ultimately in our workforce.

\section{Engagement}

Engagement has been measured in many different ways, but most studies in higher education have focused on time on task, participation in and exposure to proven teaching practices, or related measures that capture observable behaviors [13]. The National Survey on Student Engagement is the most widespread instrument in higher education for measuring engagement and assesses engagement at hundreds of higher education institutions in the United States, with the total number of participants increasing every year since its introduction in 1999 [14]. In the NSSE, engagement in academic endeavors (including courses) is measured using four scales representing academic challenge (higher order learning, reflective and integrative learning, learning strategies, and quantitative reasoning) and two scales representing experiences with faculty (student-faculty interactions and effective teaching practices). The subscales associated with the latter set of indicators (experiences with faculty) are similar to faculty support and student-faculty interaction scales used in other research efforts. In contrast, the four subscales associated with academic challenge reflect what students actually do in their academic endeavors by measuring time on task associated with the various skills that students use and develop during their college experience [15]. 
Studies which focus on the emotional aspects of engagement are not commonplace, despite the fact that both negative and positive emotions can have a wide range of distinct effects on academic achievement, motivation, persistence, and other outcomes. This study focuses on emotions through the lens of engagement to gain a greater understanding of how the negative and positive emotions that students bring into the classroom differ between majority students and under-represented groups.

\section{Negative Emotional Engagement}

A large proportion of basic and applied research in engineering education emphasizes positive academic outcomes, including cognitive (e.g. critical thinking skills), performance-based (e.g. improved grades), and emotional (e.g. interest and enthusiasm) measures. Few measures focus on more negative outcomes, ranging from drop out (i.e. failure to persist) to stress and anxiety. Of particular concern, negative emotional outcomes can and do lead to a wide variety of poor academic outcomes including lower grades, diminished learning, reduced graduation rates, and lower intentions to persist. The negative emotional engagement measure used in this study emphasizes feelings of being worried and discouraged, each of which can impair academic progress and learning.

Worry: Physiologically, worry and anxiety diminish the capacity and capability of working memory, which in turn detrimentally impact academic performance. Situational anxiety has been linked to negative academic outcomes including diminished test performance and grades [15] [16]. Anxiety and worry can also disrupt memory and the ability to recall material [18]-[20]. Anxious adults exhibit increased control of cognition only after conflicts and make more errors than their less anxious counterparts [21]. Anxiety among students can lead to poor performance because these negative emotions decrease motivation or incite withdrawal [22] which in turn reduces other forms of engagement [18].

When students enter college, the stakes are often higher than they were in high school or middle school, and students naturally worry more. In engineering, research studies have shown that stringent curriculum requirements, academic readiness, and attitudes toward learning impact students' anxiety levels [23]. Regardless of the source of this anxiety, anxiety among engineering students has been significantly correlated with low academic performance [24]. Successful teaching and mentoring of students must support anxious students in regulating their anxiety so that students are not unduly handicapped by such emotions.

Discouragement: The dictionary defines discouragement as a lack of confidence and enthusiasm. With reduced confidence, individuals tend to stay in their comfort zones, remain unwilling to take risks, struggle to remain focused, and can lose the desire and motivation to learn. Conversely, positive self-esteem and self-confidence are the cornerstone of school success and are critical to providing a necessary foundation for learning. Self-confidence is also highly correlated to self-efficacy, which reflects confidence to succeed in a specific domain like engineering [25]. Students who have reduced self-efficacy or do not exude confidence to others can also find themselves with more limited opportunities to productively work with others, which leads to a snowball effect and reduces confidence even further over the course of the undergraduate career. Low self-efficacy has been positively and significantly correlated to poor academic performance and low persistence in a wide range of subjects and disciplines [26]. 
Consistent feelings of being discouraged in a course are not simply about being in a bad mood, but instead are a handicap that, if not addressed, can carry over into other courses and into the student's early career. As young professionals, these individuals may continue to remain in their comfort zones where the threat of failure is low. Such cautious behavior can lead to a young engineer remaining in bad work situations, avoiding new or challenging assignments, or being reluctant to seek out new positions, all of which place limitations on career and quality of life and prevent that person's full potential and contribution to society from being realized.

Measures: in K-12 studies [27], negative emotional engagement has been assessed using multiple scales measuring anxiety, anger, and boredom in the classroom separately. When items from these scales were piloted in a multiple-institution study of engagement among engineering students [28], however, only a single factor emerged from exploratory factor analyses to measure negative emotions in the classroom and this single factor covered feelings of both worry and discouragement. Items which referenced feeling bad, bored, or disinterested failed to adequately load onto a single scale, suggesting that among college students, these feelings overlap onto multiple constructs.

\section{Positive Emotional Engagement}

Whereas the higher education literature emphasizes positive academic outcomes such as academic achievement, effort, and persistence, the psychology literature emphasizes the study of negative emotions in these contexts. Traditional psychological theories which consider positive emotions have tended to emphasize how positive emotions (particularly those of high-intensity) negatively impact attention and regulation [29]. In the past decade however, positive emotions and the positive impacts of those emotions on academic achievement and performance have attracted increased interest from both the psychology and education communities. Positive emotions are key elements to human adaption and learning and while high-intensity emotions may impair attention, focus, and motivation, low-intensity positive emotions are likely to do the opposite by increasing the ability to regulate behavior [29]. For example, enjoyment is a lowintensity emotion that has been linked to better academic performance [30][31][32]. Lowintensity positive emotions can also promote better cognitive and academic functioning by broadening cognition and awareness of potential solutions to difficult problems [33]. Further, another low-intensity emotion, interest, is likely to help students pay attention and in so doing, perform better [29]. Interest and curiosity are likely to result in higher achievement by increasing motivation to seek out additional learning resources [29] and enhancing intrinsic motivation and locus of control [34].

Measures: in K-12 studies [27], positive emotions in the academic context have been assessed using multiple scales measuring enjoyment and curiosity. When items from these scales were piloted in a multiple-institution study of engagement among engineering students [35], however, only a single factor emerged from exploratory factor analyses to measure positive emotions in the classroom and this measure covered low-intensity emotions of interest, fun, and enjoyment.

\section{Research Questions}

This study was guided by a single research question:

RQ: Does under-represented status predict students' emotional engagement? 
Minority status was studied in terms of gender (female vs. male), race/ethnicity (non-White, nonAsian vs. White), international student status (U.S. citizens/permanent residents vs. international students), and family education (first-generation vs. families with at least one college degree). Understanding the emotional experiences of under-represented groups in the classroom is a key component of understanding how to better bolster these minority groups so that they operate on a level playing field in terms of learning and achieving in engineering settings.

\section{Methods}

This study analyzes student survey data using statistical methods in a quantitative research design. Students in seven, large undergraduate engineering courses representing four different engineering majors self-reported demographic information and emotional engagement as part of a larger study that explored different factors which may inform student engagement in engineering classrooms.

\section{Participants}

The sample population in this study consisted of 781 undergraduate engineering students recruited in the last two weeks of the term. Self-reported ethnicity included Asian (47\%), Black (3.5\%), Hispanic (3.5\%), White (41\%), Pacific-Islander (less than 1\%), Native American (less than $1 \%$ ), and Other (3\%). $24 \%$ of the sample were female, $75 \%$ were male, and less than $1 \%$ reported Other. Only female and male students were retained for this study. Students reported their country of origin as either U.S. citizens (77\%), Permanent Residents (4.8\%), International $(17.7 \%)$, or Other (less than 1\%). ANOVA results indicated that U.S. citizens and permanent residents performed with similar engagement levels. Therefore, these groups were consolidated into a single group including both U.S. citizens and permanent residents. First-generation students were those who reported that neither their mother or father had completed a college degree and represented $13.6 \%$ of the sample population.

\section{Procedures}

IRB (Internal Review Board) approval was obtained to recruit and survey 781 undergraduate students for this study. All participation was voluntary, and students were informed that their survey responses would remain confidential. In several courses, students were incentivized with a nominal amount of extra credit for the course in which they were recruited. All students completed an electronic survey online and outside of class. Surveys were collected with identifying information so that duplicates could be removed before aggregating data for analysis. All results were cross-sectional. Students reported their perceptions of various items related to engagement, belonging, effort, peer harassment, task value, self-efficacy, TA and faculty interactions, and measures of course achievement as well as responding to demographic items.

\section{Data Analysis}

The data were analyzed using SPSS 19. Descriptive statistics (mean, standard deviation) were computed for all instructional support (independent variables) and engagement measures (dependent variables). Exploratory factor analyses using principal component analysis with varimax rotation were performed on the instructional support items in the survey to identify suitable scales to represent TA and faculty behaviors. Pearson bivariate correlations were evaluated between engagement variables and between instructional support variables to identify the possibility that multiple scales could be measuring the same thing. 
Once the scales were finalized, a four-level linear regression model was constructed for each of the two measures of emotional engagement (positive and negative). The first level of the model contained the four demographic categories effect coded as shown in Table 1. Asian students were not included in this analysis because although they are a minority in the general population, they are not under-represented in engineering. The second level of the model contained variables representing instructor interactions and the third level added measures of both TA and faculty support. The last level of the model considered any interactions between demographics and TA/faculty support and interactions relevant to the optimized (most parsimonious) model. The optimized regression model was selected based on finding a minimum Bayesian (BIC) and Akaike information (AIC) criterion by adding independent interaction variables to the model one at a time to evaluate their impact on the AIC and BIC. Interaction variables that resulted in a decrease in BIC or AIC of more than 1 were retained while other interaction variables were eliminated from the model.

Finally, a mixed model using HLM (hierarchical linear modelling) was constructed to understand whether nesting of students within TA sections and within courses affected the engagement variables. The results of a null HLM model (i.e. one that did not contain the independent variables) confirmed that the variance contributed to both forms of engagement at the TA level and course level was not significant. Thus, the results of hierarchical regression are unlikely to be confounded by nesting effects, making this approach to data analysis appropriate for this data.

Table 1: Effect Coding of Independent Variables for Linear Regression Models

\begin{tabular}{|l|c|c|}
\hline Characteristic & Variable Name(s) & Effect Coding \\
\hline Gender & Gender & Male $=-1$; Female $=1$ \\
\hline Race/Ethnicity & URM & White $=-1$; Asian $=0$; Other $($ URM) $=1$ \\
\hline Family of Origin & First-Generation & $\begin{array}{l}\text { Father, Mother, or both have College Degree }=-1 \\
\text { Neither Father or Mother have College Degree }=1\end{array}$ \\
\hline Country of Origin & International & $\begin{array}{r}\text { U.S. or permanent resident }=-1 \\
\text { International student }=1\end{array}$ \\
\hline
\end{tabular}

\section{Measures}

The analysis reported in this paper focuses on two primary engagement variables, multiple instructor/teacher related variables, and four demographic measures (gender, race/ethnicity, family education, and country of origin). The two engagement variables are listed by category in Table 2 along with sample items and Cronbach's reliability coefficients. The emotional engagement scales were adapted from Miserandino [27] and tested in a higher education setting [35] to measure students' affective responses to their courses. Positive Emotional Engagement measured positive emotional levels students felt about learning and being in class while Negative Emotional Engagement measured the negative feelings that students felt about learning and being in their classes. Although negative emotional engagement had an internal reliability that was less than the standard 0.7 , there is evidence that reliability between 0.6 and 0.7 is adequate [36]. Therefore, both engagement variables were retained for analysis. 
Table 2: Emotional Engagement (Dependent) Variables

\begin{tabular}{ll}
\hline Primary Scale & Sample Item \\
\hline Positive Emotional Engagement $(\alpha=0.75)$ & I enjoy learning new things in this class. \\
Negative Emotional Engagement $(\alpha=0.67)$ & In this class, I feel discouraged. \\
\hline
\end{tabular}

The independent variables used to represent the behaviors of faculty in this study were adapted from previous measures of academic support, teaching practices, faculty contact, and observations of instructor behavior in engineering classrooms. Four items were used from engagement indicators related to teaching practices in the National Survey of Student Engagement [15], five items were adapted from the teacher academic support subscale developed by Van Ryzin et al. [37] and six items were adapted from the faculty contact scale used by Einarson and Clarkberg [38]. An additional six items were also added to assess faculty support based on observations of classrooms and interactions in a previous study [39]. In total, 21 items were developed to assess faculty behaviors, a majority of which were adapted from scales used to measure primary instructor (e.g. faculty) support in the classroom. These same 21 items were also adapted for measuring TA behaviors.

Table 3: Instructional Support (Independent) Variables

\begin{tabular}{|c|c|}
\hline Scale & Sample Items \\
\hline \multirow{3}{*}{$\begin{array}{l}\text { Faculty } \\
\text { Support } \\
(\alpha=0.90)\end{array}$} & The professor in this class cares about how much I learn. \\
\hline & The professor in this class treats me with respect. \\
\hline & The professor in this class is available when I need help. \\
\hline \multirow{3}{*}{$\begin{array}{l}\text { Faculty } \\
\text { Interactions } \\
(\alpha=92)\end{array}$} & I have discussed career plans with the professor in this class. \\
\hline & I have discussed academic work with the professor in this class. \\
\hline & I have discussed course selection with the professor in this class. \\
\hline \multirow{3}{*}{$\begin{array}{l}\text { TA } \\
\text { Support } \\
(\alpha=0.92)\end{array}$} & The TA in this class cares about how much I learn. \\
\hline & $\begin{array}{l}\text { The TA for my recitation or lab section in this class often stays after class to answer } \\
\text { questions. }\end{array}$ \\
\hline & $\begin{array}{l}\text { At least one of the TAs in this class has often provided feedback on a draft or } \\
\text { work/homework in progress. }\end{array}$ \\
\hline \multirow{3}{*}{$\begin{array}{l}\text { TA } \\
\text { Interactions } \\
(\alpha=0.92)\end{array}$} & I have discussed career plans with at least one of the TAs in this class. \\
\hline & I have discussed course selection with at least one of the TAs in this class. \\
\hline & I have e-mailed at least one of the TAs in this class for assistance. \\
\hline
\end{tabular}

Exploratory factor analyses (EFA) were conducted independently on the 21 faculty behavior items and on the $21 \mathrm{TA}$ behavior items using varimax rotation to identify usable scales for this study. The number of factors was initially determined by an eigenvalue threshold of 1 while also considering the point at which the scree plot for the eigenvalues levelled off and adding additional factors explained little additional variance in the data. Items that demonstrated communalities of less than 0.5 and failed to demonstrate a strong $(>0.6)$ loading on any single 
factor were discarded. Items that loaded onto more than one factor $(>0.4)$ were also discarded. After items were discarded, any remaining factors which contained at least two items were retained for analysis. The results of this EFA produced four measures: faculty support, TA support, faculty interactions, and TA interactions. Sample items associated with each of these four measures are summarized in Table 3. The Pearson bivariate correlation between faculty interactions and TA interactions was very high (0.89) and the resulting regression models dropped faculty interactions because their impact on the information criteria (AIC and BIC) was detrimental to model quality.

\section{Results \& Discussion}

Descriptive statistics for the faculty and TA support, faculty and TA interactions, as well as positive and negative emotional engagement for the four demographic groups are summarized in Table 4.

Table 4: Descriptive Statistics

Faculty TA Engagement

\begin{tabular}{|c|c|c|c|c|c|c|}
\hline & Support & Interactions & Support & Interactions & Positive & Negative \\
\hline \multicolumn{7}{|l|}{ All Students } \\
\hline$N$ & 690 & 696 & 648 & 707 & 704 & 715 \\
\hline Mean (SD) & $3.96(0.64)$ & $1.72(0.90)$ & $3.55(0.80)$ & $1.56(0.87)$ & $3.46(0.77)$ & $3.14(0.95)$ \\
\hline Gender & & $* *$ & & $* *$ & & \\
\hline Males & $3.96(0.65)$ & $1.77(0.94)$ & $3.57(0.80)$ & $1.61(0.92)$ & $3.50(0.77)$ & $3.18(0.95)$ \\
\hline Females & $3.97(0.60)$ & $1.56(0.73)$ & $3.54(0.77)$ & $1.42(0.66)$ & $3.38(0.75)$ & $3.02(0.94)$ \\
\hline Race/Ethnicity & & $* *$ & $* *$ & $* * *$ & & $* *$ \\
\hline White & $4.00(0.61)$ & $1.60(0.80)$ & $3.41(0.82)$ & $1.39(0.69)$ & $3.42(0.77)$ & $3.29(0.92)$ \\
\hline Asian & $3.92(0.64)$ & $1.80(0.93)$ & $3.65(0.74)$ & $1.69(0.92)$ & $3.48(0.77)$ & $3.05(0.96)$ \\
\hline URM & $3.99(0.66)$ & $1.87(1.04)$ & $3.66(0.84)$ & $1.66(1.10)$ & $3.55(0.75)$ & $3.05(0.99)$ \\
\hline Citizenship & & $* * *$ & $* * *$ & $* * *$ & $* * *$ & \\
\hline U.S. & $3.97(0.62)$ & $1.66(0.86)$ & $3.49(0.80)$ & $1.48(0.80)$ & $3.41(0.75)$ & $3.17(0.94)$ \\
\hline International & $3.95(0.68)$ & $2.05(1.01)$ & $3.83(0.71)$ & $1.97(1.04)$ & $3.71(0.80)$ & $3.05(0.96)$ \\
\hline \multicolumn{7}{|l|}{ Family Ed } \\
\hline College Degree & $3.97(0.43)$ & $1.72(0.89)$ & $3.54(0.80)$ & $1.55(0.85)$ & $3.46(0.78)$ & $3.15(0.96)$ \\
\hline First Gen & $3.95(0.63)$ & $1.74(0.93)$ & $3.61(0.75)$ & $1.58(0.94)$ & $3.48(0.74)$ & $3.15(0.89)$ \\
\hline
\end{tabular}

Independent samples t-tests between genders (male, female) showed that male students reported significantly higher levels of faculty and TA interactions than female students. Between domestic and international students, international students reported significantly higher levels of faculty interactions, TA support, TA interactions, and positive emotional engagement than U.S. citizens and permanent residents. And within family education levels, no significant differences in any of the independent or dependent variables emerged. One-way analysis of variance (ANOVA) demonstrated significant differences in faculty and TA interactions, TA support, and negative emotional engagement among race/ethnicity groups. Follow-up pairwise comparisons 
revealed that White students reported significantly lower interactions with faculty and TAs and significantly lower perceptions of TA support than both Asian and URM students. White students also reported significantly better levels of negative emotional engagement than Asian students, but no significant pairwise differences emerged in comparing the negative emotional engagement of White with that of URM students.

To better understand how being a member of a particular demographic group contributed to both positive and negative emotional engagement, two four-level regression models were constructed for forms of engagement. A summary of the characteristics for each of these models including the two information criteria (AIC and BIC) for the most parsimonious model obtained as described in the Data Analysis section is provided in Table 5. The $\mathrm{R}^{2}$ goodness of fit measure for the first model (which included only demographics) was low for both forms of engagement, explaining only $2.0 \%$ and $1.5 \%$ of the variability in the data for positive and negative emotional engagement respectively. $\mathrm{R}^{2}$ increased significantly for subsequent levels of each model, but the improvement in fit was greatest for positive emotional engagement.

Table 5: Summary of Linear Regression Models for Emotional Engagement

\begin{tabular}{lccc}
\hline & Model 1 & Model 2 & Model 3 \\
\hline $\begin{array}{l}\text { Independent } \\
\text { Variables }\end{array}$ & Female & Instructor & Faculty Support \\
& URM & TA Support \\
& First-Generation & Contact & \\
\hline International & $\mathrm{R}^{2}=0.020$ & $\mathrm{R}^{2}=0.119$ & $\mathrm{R}^{2}=0.546$ \\
Positive & $\mathrm{SE}=0.755$ & $\mathrm{SE}=0.716$ & $\mathrm{SE}=0.515$ \\
Engagemal & $\mathrm{AIC}=-325.5$ & $\mathrm{AIC}=-386.4$ & $\mathrm{AIC}=-772.6$ \\
& $\mathrm{BIC}=-303.6$ & $\mathrm{BIC}=-360.1$ & $\mathrm{BIC}=-737.5$ \\
\hline Negative & $\mathrm{R}=0.015$ & $\mathrm{R} 2=0.083$ & $\mathrm{R}=0.145$ \\
Emotional & $\mathrm{SE}=0.944$ & $\mathrm{SE}=0.911$ & $\mathrm{SE}=0.811$ \\
Engagement & $\mathrm{AIC}=-63.48$ & $\mathrm{AIC}=-103.7$ & $\mathrm{AIC}=-141.2$ \\
& $\mathrm{BIC}=-41.59$ & $\mathrm{BIC}=-77.39$ & $\mathrm{BIC}=-106.2$ \\
\hline
\end{tabular}

\section{Research Question:}

Does under-represented status predict students' emotional engagement?

When engagement is measured at an emotional level, under-represented status predicts some forms of emotional engagement and not others.

\section{Positive Emotional Engagement}

Minority status as measured by gender (female), race (neither White nor Asian), and family education (e.g. first-generation status) does not predict positive emotional engagement in any of the regression models constructed in this study (Table 6). Further, while international status is significantly associated with positive emotional engagement in the first regression model, this model is weak $\left(\mathrm{R}^{2}=0.020\right)$ compared to the remaining models, and in the stronger models (Model 2, 3, 4), this association becomes insignificant. 
Table 6: Hierarchical Regression Models for Positive Emotional Engagement

\begin{tabular}{|c|c|c|c|c|c|c|c|c|c|c|c|c|}
\hline \multirow{2}{*}{$\begin{array}{c}\text { Predictor } \\
\text { Variable } \\
\end{array}$} & \multicolumn{3}{|c|}{ Model 1} & \multicolumn{3}{|c|}{ Model 2} & \multicolumn{3}{|c|}{ Model 3} & \multicolumn{3}{|c|}{ Model 4} \\
\hline & $\begin{array}{c}\mathrm{B} \\
(\mathrm{SE})\end{array}$ & $p$ & & $\begin{array}{c}\mathrm{B} \\
(\mathrm{SE}) \\
\end{array}$ & $p$ & & $\begin{array}{c}\mathrm{B} \\
(\mathrm{SE})\end{array}$ & $p$ & & $\begin{array}{c}\mathrm{B} \\
(\mathrm{SE}) \\
\end{array}$ & $p$ & \\
\hline Constant & $\begin{array}{c}3.542 \\
(0.056)\end{array}$ & 0.000 & $* * *$ & $\begin{array}{c}3.057 \\
(0.080)\end{array}$ & 0.000 & $* * *$ & $\begin{array}{c}0.093 \\
(0.152)\end{array}$ & 0.539 & & $\begin{array}{c}0.240 \\
(0.160)\end{array}$ & 0.135 & \\
\hline Gender & $\begin{array}{l}-0.034 \\
(0.036)\end{array}$ & 0.346 & & $\begin{array}{l}-0.005 \\
(0.035)\end{array}$ & 0.888 & & $\begin{array}{l}-0.035 \\
(0.025)\end{array}$ & 0.166 & & $\begin{array}{l}-0.034 \\
(0.025)\end{array}$ & 0.167 & \\
\hline URM & $\begin{array}{c}0.048 \\
(0.049)\end{array}$ & 0.323 & & $\begin{array}{c}0.010 \\
(0.046)\end{array}$ & 0.832 & & $\begin{array}{l}-0.028 \\
(0.034)\end{array}$ & 0.412 & & $\begin{array}{l}-0.024 \\
(0.033)\end{array}$ & 0.480 & \\
\hline $\begin{array}{c}\text { First } \\
\text { Generation }\end{array}$ & $\begin{array}{c}0.036 \\
(0.046)\end{array}$ & 0.428 & & $\begin{array}{c}0.042 \\
(0.043)\end{array}$ & 0.329 & & $\begin{array}{c}0.021 \\
(0.031)\end{array}$ & 0.494 & & $\begin{array}{c}0.025 \\
(0.031)\end{array}$ & 0.429 & \\
\hline International & $\begin{array}{c}0.108 \\
(0.042) \\
\end{array}$ & 0.010 & $*$ & $\begin{array}{c}0.043 \\
(0.041) \\
\end{array}$ & 0.293 & & $\begin{array}{c}0.017 \\
(0.029) \\
\end{array}$ & 0.566 & & $\begin{array}{c}0.013 \\
(0.029) \\
\end{array}$ & 0.655 & \\
\hline $\begin{array}{l}\text { Instructor } \\
\text { Interactions }\end{array}$ & & & & $\begin{array}{c}0.298 \\
(0.037)\end{array}$ & 0.000 & $* * *$ & $\begin{array}{c}0.111 \\
(0.028)\end{array}$ & 0.000 & $* * *$ & $\begin{array}{c}0.125 \\
(0.028) \\
\end{array}$ & 0.000 & $* * *$ \\
\hline $\begin{array}{l}\text { Faculty } \\
\text { Support }\end{array}$ & & & & & & & $\begin{array}{c}0.329 \\
(0.036)\end{array}$ & 0.000 & $* * *$ & $\begin{array}{c}0.291 \\
(0.038)\end{array}$ & 0.000 & $* * *$ \\
\hline $\begin{array}{c}\text { TA } \\
\text { Support }\end{array}$ & & & & & & & $\begin{array}{c}0.531 \\
(0.030)\end{array}$ & 0.000 & $* * *$ & $\begin{array}{c}0.526 \\
(0.030)\end{array}$ & 0.000 & $* * *$ \\
\hline $\begin{array}{l}\text { URM X } \\
\text { Faculty } \\
\text { Support }\end{array}$ & & & & & & & & & & $\begin{array}{l}-0.089 \\
(0.032)\end{array}$ & 0.006 & $* *$ \\
\hline
\end{tabular}

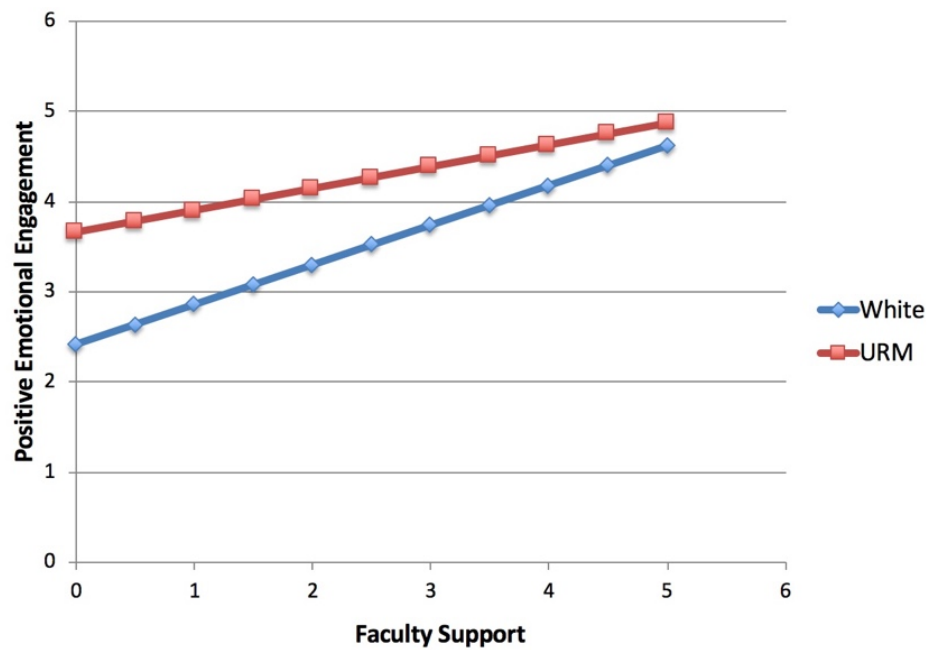

Figure 1
One significant interaction emerged in the model for positive emotional engagement (Model 4 in Table 6). Figure 1 provides a closer look at this interaction. White students tend to experience fewer positive emotions with less faculty support than URM students do. This interaction suggests that URM students may be more resilient to fluctuations in faculty support while White students may have higher expectations.

\section{Interaction Effects associated with URM Status}

Unfortunately, these lower expectations may be a direct result of faculty behavior toward URM students. URM students report that faculty often have lower expectations for them, do not care, or do not have time for them. URM students also report that faculty do not seem to understand that they are different from White students and as a result, feel excluded and on the periphery of 
classroom culture [40]. Such entrenched feelings of marginalization are likely to lead to lower expectations which in turn, may cause URM students to be less responsive to faculty support.

\section{Negative Emotional Engagement}

While being female is not associated with positive emotional engagement in any way (Table 6), being female does negatively predict negative emotional engagement in the higher level models of the linear regression. In the first model that considers only demographic variables, being female does not predict negative emotional engagement. In this first model, the four demographic variables only predicted $1.5 \%$ of the variability $\left(\mathrm{R}^{2}=0.015\right)$ in negative emotional engagement. In subsequent models where more of the variability in negative emotional engagement is explained (8.3\% in Model 2 and 14.5\% in Model 3), gender significantly and negatively predicted negative emotional engagement. Translated, this means that when considering TA and faculty support as well as instructor interactions, being female led to more feelings of anxiety and discouragement.

Table 7: Hierarchical Regression Models for Negative Emotional Engagement

\begin{tabular}{|c|c|c|c|c|c|c|c|c|c|c|c|c|}
\hline \multirow{2}{*}{$\begin{array}{c}\text { Predictor } \\
\text { Variable } \\
\end{array}$} & \multicolumn{3}{|c|}{ Model 1} & \multicolumn{3}{|c|}{ Model 2} & \multicolumn{3}{|c|}{ Model 3} & \multicolumn{3}{|c|}{ Model 4} \\
\hline & $\begin{array}{c}\mathrm{B} \\
(\mathrm{SE})\end{array}$ & $p$ & & $\begin{array}{c}\mathrm{B} \\
(\mathrm{SE})\end{array}$ & $p$ & & $\begin{array}{c}\mathrm{B} \\
(\mathrm{SE})\end{array}$ & $p$ & & $\begin{array}{c}\mathrm{B} \\
(\mathrm{SE})\end{array}$ & $p$ & \\
\hline Constant & $\begin{array}{l}3.102 \\
(0.07)\end{array}$ & 0.00 & $* * *$ & $\begin{array}{c}3.603 \\
(0.102)\end{array}$ & 0.00 & $* * *$ & $\begin{array}{c}2.13 \\
(0.026)\end{array}$ & 0.00 & $* * *$ & $\begin{array}{c}2.596 \\
(0.301)\end{array}$ & 0.00 & $* * *$ \\
\hline Gender & $\begin{array}{l}-0.071 \\
(0.045)\end{array}$ & 0.12 & & $\begin{array}{l}-0.097 \\
(0.044)\end{array}$ & 0.03 & * & $\begin{array}{l}-0.109 \\
(0.043)\end{array}$ & 0.01 & * & $\begin{array}{l}-0.105 \\
(0.042)\end{array}$ & 0.01 & $*$ \\
\hline URM & $\begin{array}{l}-0.151 \\
(0.061)\end{array}$ & 0.01 & * & $\begin{array}{l}-0.112 \\
(0.059)\end{array}$ & 0.06 & & $\begin{array}{l}-0.125 \\
(0.057)\end{array}$ & 0.03 & $*$ & $\begin{array}{l}-0.128 \\
(0.057)\end{array}$ & 0.03 & $*$ \\
\hline First Gen & $\begin{array}{c}0.051 \\
(0.057)\end{array}$ & 0.37 & & $\begin{array}{c}0.040 \\
(0.055)\end{array}$ & 0.47 & & $\begin{array}{c}0.028 \\
(0.053)\end{array}$ & 0.60 & & $\begin{array}{c}0.022 \\
(0.053)\end{array}$ & 0.68 & \\
\hline Intl & $\begin{array}{c}0.002 \\
(0.052) \\
\end{array}$ & 0.97 & & $\begin{array}{c}0.069 \\
(0.052) \\
\end{array}$ & 0.18 & & $\begin{array}{c}0.059 \\
(0.050) \\
\end{array}$ & 0.24 & & $\begin{array}{c}0.022 \\
(0.054) \\
\end{array}$ & 0.18 & \\
\hline $\begin{array}{l}\text { Instructor } \\
\text { Interact }\end{array}$ & & & & $\begin{array}{c}-0.311 \\
(0.047)\end{array}$ & 0.00 & $* * *$ & $\begin{array}{l}-0.400 \\
(0.048)\end{array}$ & 0.00 & $* * *$ & $\begin{array}{c}-0.384 \\
(0.048)\end{array}$ & 0.00 & $* * *$ \\
\hline $\begin{array}{l}\text { Faculty } \\
\text { Support }\end{array}$ & & & & & & & $\begin{array}{c}0.190 \\
(0.051)\end{array}$ & 0.002 & $* *$ & $\begin{array}{l}-0.130 \\
(0.092)\end{array}$ & 0.16 & \\
\hline $\begin{array}{c}\text { TA } \\
\text { Support }\end{array}$ & & & & & & & $\begin{array}{c}0.233 \\
(0.051)\end{array}$ & 0.00 & $* * *$ & $\begin{array}{c}0.166 \\
(0.089)\end{array}$ & 0.06 & \\
\hline $\begin{array}{c}\text { Intl X } \\
\text { Faculty } \\
\text { Support }\end{array}$ & & & & & & & & & & $\begin{array}{l}-0.084 \\
(0.058)\end{array}$ & 0.15 & \\
\hline $\begin{array}{c}\text { Intl X } \\
\text { TA } \\
\text { Support }\end{array}$ & & & & & & & & & & $\begin{array}{l}-0.078 \\
(0.069)\end{array}$ & 0.26 & \\
\hline
\end{tabular}

One possible explanation of this result is that instructor contact may have a compensating effect on feelings of anxiety and discouragement among women. Female students may, in general, have negative feelings about their engineering courses compared to male students, but when they experience meaningful interactions with TAs and faculty, these feelings may lessen. To explore this possibility, instructor contact was organized into two (binary) categories: (a) high instructor contact indicated by average Likert scale scores greater than 2.5; and (b) low instructor contact 
indicated by scores lower than 2.5. An independent samples t-test of gender differences within these two categories indicated that for those students that reported low or infrequent instructor contact, the negative emotional engagement scores for women were significantly lower (worse than those for men $(p=0.013)$. However, for students who reported high levels of instructor contact, no significant gender differences in negative emotional engagement were evident. This strongly suggests that instructor interactions with female students may offset or mitigate negative feelings and enable them to engage at emotional levels on par with men. Since this study is cross-sectional, causality cannot be concluded and a longitudinal study would be needed to fully explore this hypothesis.

Instructor interactions can be both formal and informal and can be situated in the context of a more authoritative relationship (i.e. student-faculty) or a more peer-oriented relationship (i.e. student-TA). While instructor interactions can serve to build confidence and familiarity with course material, female students may also benefit from instructor interactions through an increased sense of belonging. Course-related faculty interactions and faculty mentoring have been linked to an increased sense of belonging as have discussions with peers (and by extension, instructors like TAs who in part act as peers) about academic and career issues [41]. In turn, a sense of belonging is negatively correlated to feelings of loneliness, anxiety, and depression among college students [42]. In this study, similar results emerged among under-represented racial/ethnic minority (URM) students ( $85.2 \%$ of which were male). Those URM students who had high levels of interaction with instructors reported negative emotional engagement levels that were not significantly different than their White classmates while those URM students who had low levels of interaction with instructors reported significantly worse levels of negative emotional engagement than their White classmates $(p=0.03)$.

Overall, instructor interactions negatively and significantly predicted negative emotional engagement. This reaffirms the notion that instructor interaction serves a compensatory function rather than a bolstering function. Since negative emotional engagement was coded such that higher reports mean less negative feelings, this means that those students who have strong negative feelings about a course are also those students who have high levels of interaction with instructors. While this could mean that the instructors are simply generating negative feelings among students by virtue of interacting with them, this conclusion is unlikely because both faculty and TA support predict lesser feelings of anxiety and discouragement. The more likely explanation is that instructor interactions are sought out by students who come into a course already feeling stressed or worried.

\section{Limitations and Implications}

While this study has provided evidence of gender differences in positive and negative emotional engagement in engineering courses and suggested that interactions with both faculty and TAs are likely to reduce the gender gap in engagement levels, it does have its limitations. For one, the data is limited to a single institution, and therefore these findings may not generalize to other institutions of higher education. The study is also cross-sectional and causality may be suggested but is certainly not proven. While further research is merited particularly that involving more courses across multiple institutions, the results here reinforce the existing literature regarding the important role that all instructors (faculty and TAs) are likely to play in bolstering underrepresented groups in levelling the playing field. Furthermore, the results of this study have 
important implications to TA and faculty development in that techniques to appropriately and effectively interact with and support females as well as non-White, non-Asian students are an essential part of initial and ongoing teacher training.

\section{Concluding Remarks}

This study has complemented the existing literature that stresses the importance of both faculty instructional support and student-faculty interactions. Not only are both faculty and TAs important in building engagement among all types of students, but the influence of faculty and TAs appears to be especially instrumental in bolstering the feelings that under-represented groups (particularly females and non-White, non-Asian students) have in the classroom. These feelings (emotional engagement) are critical to both cognitive performance and building a sense of belonging among these groups. When student-faculty and student-TA interactions are frequent and positive for these under-represented groups, the engagement gap disappears and the playing field levels out for these students compared to their White peers. While future work should further explore the closing of these engagement gaps across more courses and multiple institutions on a longitudinal scale, the present results speak strongly to the importance of attending to not only what students do (as in many traditional measures of engagement), but also how they feel.

\section{Acknowledgments}

The author would like to gratefully acknowledge the National Science Foundation for their support of this work (DUE grant number 1504618). Any opinions, findings, and conclusions or recommendations expressed in this material are those of the author(s) and do not necessarily reflect the views of the National Science Foundation. The author would also like to thank the statistical consulting resources provided by the Center for Statistics and the Social Sciences, University of Washington.

\section{References}

[1] U.S. Census Bureau, "QuickFacts: United States," 2019. https://www.census.gov/quickfacts/fact/table/US/LFE046218 (accessed Jan. 28, 2020).

[2] National Science Foundation, "Women, Minorities, and Persons with Disabilities Report," 2019. https://www.nsf.gov/news/news_summ.jsp?cntn_id=297944 (accessed Jan. 28, 2020).

[3] National Science Foundation, "Women, Minorities, and Persons with Disabilities in Science and Engineering." https:/www.nsf.gov/statistics/2017/nsf17310/\#engineering (accessed Apr. 08, 2020).

[4] C. Corbett and C. Hill, "Solving the Equation: The Variables for Women's Success in Engineering and Computing," AAUW: Empowering Women Since 1881. https://www.aauw.org/research/solving-the-equation/ (accessed Jan. 18, 2019).

[5] C. B. Muller, "The underrepresentation of women in engineering and related sciences: Pursuing two complementary paths to parity," in Pan-Organizational Summit on the US Science and Engineering Workforce: Meeting Summary, 2003, pp. 119-126.

[6] American Physical Society, "Bachelor's Degrees Earned by Women, by Major." https://www.aps.org/programs/education/statistics/womenmajors.cfm (accessed Jan. 28, 2020). 
[7] W. Wulf, "Diversity in engineering," The Bridge, vol. 28, no. 4, 1998.

[8] Pew Research Center, "Asians and whites are overrepresented in STEM jobs, while Hispanics and blacks are underrepresented," Pew Research Center, 2018. Accessed: Feb. 29, 2020. [Online]. Available: https://www.pewsocialtrends.org/2018/01/09/women-andmen-in-stem-often-at-odds-over-workplace-equity/ps_2018-01-09_stem_a-08/.

[9] L. Eismann, "First-Generation Students and Job Success." National Association of Colleges and Employers, Nov. 01, 2016, [Online]. Available: https://www.naceweb.org/jobmarket/special-populations/first-generation-students-and-job-success/.

[10] D. Verdin and A. Godwin, "First in the family: A comparison of first-generation and nonfirst-generation engineering college students," in 2015 IEEE Frontiers in Education Conference (FIE), Camino Real El Paso, El Paso, TX, USA, Oct. 2015, pp. 1-8, doi: 10.1109/FIE.2015.7344359.

[11] Institute of International Education, "Number of International Students in the United States Hits All-Time High,” iie, 2019. https:/www.iie.org:443/en/Why-

IIE/Announcements/2019/11/Number-of-International-Students-in-the-United-States-HitsAll-Time-High (accessed Jan. 28, 2020).

[12] J. J. Lee and C. Rice, "Welcome to America? International student perceptions of discrimination," High. Educ., vol. 53, no. 3, pp. 381-409, Mar. 2007, doi: 10.1007/s10734005-4508-3.

[13] L. Wolf-Wendel, K. Ward, and J. Kinzie, “A tangled web of terms: The overlap and unique contribution of involvement, engagement, and integration to understanding college student success," J. Coll. Stud. Dev., vol. 50, no. 4, pp. 407-428, 2009.

[14] National Survey on Student Engagement, "About NSSE." https://nsse.indiana.edu/html/about.cfm (accessed Feb. 02, 2020).

[15] National Survey on Student Engagement, "NSSE Engagement Indicators," 2019. http://nsse.indiana.edu/html/engagement_indicators.cfm (accessed Feb. 02, 2020).

[16] S. Duchesne, F. Vitaro, S. Larose, and R. E. Tremblay, "Trajectories of anxiety during elementary-school years and the prediction of high school noncompletion," J. Youth Adolesc., vol. 37, no. 9, pp. 1134-1146, 2008.

[17] B. Seipp, “Anxiety and academic performance: A meta-analysis of findings," Anxiety Res., vol. 4, no. 1, pp. 27-41, 1991.

[18] E. A. Linnenbrink, "The role of affect in student learning: A multi-dimensional approach to considering the interaction of affect, motivation, and engagement," in Emotion in education, Elsevier, 2007, pp. 107-124.

[19] E. A. Linnenbrink, A. M. Ryan, and P. R. Pintrich, "The role of goals and affect in working memory functioning," Learn. Individ. Differ., vol. 11, no. 2, pp. 213-230, 1999.

[20] J. A. Rice, L. J. Levine, and D. A. Pizarro, “" Just stop thinking about it': Effects of emotional disengagement on children's memory for educational material.," Emotion, vol. 7, no. 4, p. 812, 2007.

[21] H. Van Steenbergen, G. P. Band, and B. Hommel, "In the mood for adaptation: How affect regulates conflict-driven control," Psychol. Sci., vol. 21, no. 11, pp. 1629-1634, 2010.

[22] R. J. Davidson, D. C. Jackson, and N. H. Kalin, "Emotion, plasticity, context, and regulation: perspectives from affective neuroscience.," Psychol. Bull., vol. 126, no. 6, p. $890,2000$.

[23] L. E. Bernold, J. E. Spurlin, and C. M. Anson, "Understanding Our Students: A Longitudinal-Study of Success and Failure in Engineering With Implications for Increased 
Retention," J. Eng. Educ., vol. 96, no. 3, pp. 263-274, 2007, doi: 10.1002/j.21689830.2007.tb00935.x.

[24] P. Vitasari, M. N. A. Wahab, A. Othman, T. Herawan, and S. K. Sinnadurai, "The Relationship between Study Anxiety and Academic Performance among Engineering Students," Procedia - Soc. Behav. Sci., vol. 8, pp. 490-497, Jan. 2010, doi: 10.1016/j.sbspro.2010.12.067.

[25] J. Lane, A. M. Lane, and A. Kyprianou, "Self-efficacy, self-esteem and their impact on academic performance," Soc. Behav. Personal. Int. J., vol. 32, no. 3, pp. 247-256, 2004.

[26] K. D. Multon, S. D. Brown, and R. W. Lent, "Relation of self-efficacy beliefs to academic outcomes: A meta-analytic investigation.," J. Couns. Psychol., vol. 38, no. 1, p. 30, 1991.

[27] M. Miserandino, "Children who do well in school: Individual differences in perceived competence and autonomy in above-average children," J. Educ. Psychol., vol. 88, no. 2, pp. 203-214, 1996, doi: 10.1037/0022-0663.88.2.203.

[28] T. Floyd-Smith et al., "A multi-institutional study of connection, community and engagement in STEM education: conceptual model development," in Proc., ASEE Annual Conference, Louisville, KY, 2010.

[29] C. Valiente, J. Swanson, and N. Eisenberg, "Linking Students' Emotions and Academic Achievement: When and Why Emotions Matter," Child Dev. Perspect., vol. 6, no. 2, pp. 129-135, Jun. 2012, doi: 10.1111/j.1750-8606.2011.00192.x.

[30] R. Pekrun, A. J. Elliot, and M. A. Maier, "Achievement goals and discrete achievement emotions: A theoretical model and prospective test," J. Educ. Psychol., vol. 98, no. 3, pp. 583-597, 2006, doi: 10.1037/0022-0663.98.3.583.

[31] J. Ferris and R. Gerber, "Mature-age students' feelings of enjoying learning in a further education context," Eur. J. Psychol. Educ., vol. 11, no. 1, p. 79, 1996.

[32] R. M. Puca and H.-D. Schmalt, "Task enjoyment: A mediator between achievement motives and performance," Motiv. Emot., vol. 23, no. 1, pp. 15-29, 1999.

[33] M. A. Cohn and B. L. Fredrickson, "Positive emotions," Oxf. Handb. Posit. Psychol., vol. 2, pp. 13-24, 2009.

[34] R. Pekrun, "The Control-Value Theory of Achievement Emotions: Assumptions, Corollaries, and Implications for Educational Research and Practice," Educ. Psychol. Rev., vol. 18, no. 4, pp. 315-341, Dec. 2006, doi: 10.1007/s10648-006-9029-9.

[35] D. Wilson et al., "Belonging and Academic Engagement Among Undergraduate STEM Students: A Multi-institutional Study," Res. High. Educ., vol. 56, no. 7, pp. 750-776, Nov. 2015, doi: 10.1007/s11162-015-9367-x.

[36] D. George and P. Mallery, SPSS for Windows step by step: A simple guide and reference, 4th ed. Boston, MA: Allyn and Bacon, 2014.

[37] M. J. Van Ryzin, A. A. Gravely, and C. J. Roseth, "Autonomy, belongingness, and engagement in school as contributors to adolescent psychological well-being," J. Youth Adolesc., vol. 38, no. 1, pp. 1-12, 2009.

[38] M. K. Einarson and M. E. Clarkberg, "Race Differences in the Impact of Students' Out-ofClass Interactions with Faculty.," J. Profr., vol. 3, no. 2, 2010.

[39] J. Wright, D. Wilson, and L. Summers, "It's Not Just What TA's Know: Exploring the Role of Teacher Efficacy among Engineering TA's," in Proc., ASEE Annual Conference and Exposition, Tampa, Florida, 2019. 
[40] M. A. Chesler, "Perceptions of Faculty Behavior by Students of Color." The Center for Research on Learning and Teaching at the University of Michigan, 1997, [Online]. Available: https://depts.washington.edu/gs630/Spring/CRLT_no7.pdf.

[41] D. R. Johnson, "Campus Racial Climate Perceptions and Overall Sense of Belonging Among Racially Diverse Women in STEM Majors," J. Coll. Stud. Dev., vol. 53, no. 2, pp. 336-346, 2012, doi: 10.1353/csd.2012.0028.

[42] B. M. Hagerty, R. A. Williams, J. C. Coyne, and M. R. Early, "Sense of belonging and indicators of social and psychological functioning," Arch. Psychiatr. Nurs., vol. 10, no. 4, pp. 235-244, Aug. 1996, doi: 10.1016/S0883-9417(96)80029-X. 